\title{
SOCIEDAD DEL CONOCIMIENTO EN MEDIO DE UNA SOCIEDAD DEL DESCONOCIMIENTO
}

\author{
José David Lara González ${ }^{1}$ \\ Benemérita Universidad Autónoma de Puebla, México
}

Resumen: El presente ensayo plantea la falacia de asumir a la sociedad actual como la sociedad del conocimiento, medio y finalidad del proyecto de globalización total del mundo. Se sostiene la presencia de los fenómenos vigentes de la sociedad de la información y de la economía del conocimiento. Desde la teoría crítica se postula la diferencia entre conocimiento y saber y el papel funcionalista que la ciencia y la tecnología tienen para el Sistema Dominante impuesto por el capitalismo neoliberal. Se anotan algunas diferencias entre la sociedad real existente y la sociedad virtual que se ha ido generando. Asimismo se establece que la sociedad del conocimiento se ve poblada por el desconocimiento y el reconocimiento.

Palabras clave: globalización, teoría crítica, modernidad, educación, tecnologización.

\section{Knowledge society in the midst of a society of ignorance}

\begin{abstract}
This paper argues the fallacy of assuming today's society as the society of knowledge, means and purpose of the project of globalization of the whole world. It supports the presence of current phenomena of the information society and knowledge economy. From critical theory postulates the difference between knowledge and learning and the functional role that science and technology have for the dominant system imposed by neoliberal capitalism. It is noted some differences between the existing real society and the virtual society that has been generated. It also states that the knowledge society is populated by ignorance and acknowledge.
\end{abstract}

Keywords: globalization, critical theory, modernity, education, technological transformation.

\section{Presentación}

En nuestro momento tardomoderno y/o posmoderno se aplica la afirmación de que vivimos en la sociedad del conocimiento. Puede ser que mucha gente no esté enterada de esto, en cambio para otras personas es algo común, incluso para otras más, es el centro de su hacer y/o de su ser y modo de ser.

\footnotetext{
1 José David Lara González es ingeniero civil. Mexicano de nacimiento. Tiene estudios de maestría en hidrología subterránea y, también de maestría en ciencias ambientales en el área de ambiente y recursos naturales. Actualmente es candidato a doctor en ciencias ambientales en el área de desarrollo sustentable y ambiente. Es profesor-investigador universitario de tiempo completo con un desempeño mayor a 25 años. Ha trabajado en proyectos de evaluación, uso, manejo y conservación de recursos naturales con énfasis en los recursos suelo y agua y, en investigaciones en el área de la educación ambiental con acento en la divulgación-difusión de la problemática socioambiental. Ha publicado ensayos y artículos en revistas nacionales e internacionales de ciencias, ciencias sociales, educación, cultura y filosofía.
} 
De manera sencilla tal vez podríamos (c)ubicar la suerte de definición de nuestra época como la de la sociedad del conocimiento como debida a que el conocimiento pasó de ser una cierta actividad centralizada en determinados "territorios o dominios" de la sociedad, a ser una especie de "destino" en el serhacer de toda la humanidad. Al mismo tiempo, podría, quizás, señalarse tal denominación como debida a que el conocimiento de formar parte de la cultura en los diversos conglomerados sociales, ha sido transformado en una nueva mercancía del más alto valor en el sistema del mercado globalizador, sistema que es el que rige las formas de producción y reproducción actuales empoderadas en el sistema dominador corriente, que es a la vez la forma de existencia presente: el neoliberalismo capitalista o hipercapitalismo.

Como componentes comunes del sistema operado y de nuestra era los distintos conocimientos repartidos en amplias áreas, se vieron fuertemente impulsados durante la etapa de los desarrollismos economicistas de la modernidad, desde la de hace siglos hasta la propia del siglo $X X$ que ahora prosigue con ciertas "adecuaciones" en estos albores del siglo XXI. El conocimiento se segmentó considerablemente dando origen a toda una vasta variedad de disciplinas y especialidades llegándose hasta la microespecificidad del conocimiento. Para el sistema dominador esto funcionó muy bien de tal modo que la ciencia y la tecnología alcanzaron, digamos en los últimos 100 años, un avance tremendo, quizás nunca antes visto.

Mecánica-automáticamente se supuso que tal avance extraordinario y muy veloz de la tecnociencia (el dueto tecnología/ciencia) era directamente lo que se había venido buscando desde hace mucho tiempo atrás: el progreso. Mismamente, se supuso abiertamente y en liberal linealidad que el progreso alcanzado era el correspondiente al desarrollo. El desarrollo era progreso y el progreso era desarrollo. Con suma alegría, los portavoces del sistema dominador cantaron la victoria de la humanidad por encima de la naturaleza e igualmente cantaban la pasmosa bienvenida final del anhelado desarrollo-progreso, hito y mito mundializados e históricos.

Las sociedades anteriores basadas en la producción en el campo y las religiosidades se veían así "superadas" y dramáticamente cambiadas a otras ya urbanas y más secularizadas donde la ciencia y la tecnología pasaron a ser nuevas fuentes de "religiosidad laica". El trabajo para la producción y reproducción humanas dejó detrás su importancia medular en el orden del sistema operado y el nuevo orden impuesto colocó al conocimiento como eje trasversal de la existencia y devenir humanos. Esto también puede verse como el cambio/mutación del papel del trabajo en la construcción humana del universo por el rol impresionante que se le ha otorgado al propio conocimiento. Hoy el conocimiento es el motor que mueve al sistema dominador mundial mientras que el mundo se dedica a la producción por medio de la explotación extremada del consumo de bienes y servicios, el cual termina siendo el sistema productivista-consumista fundado en la exponenciación de la competitividad más beligerante/agresiva.

Una característica central del sistema dominador vigente es la elevada velocidad en su fuero. La velocidad es mayor cada vez, esto es, el quehacer y la vida se 
aceleran constantemente. Otra propiedad del mismo sistema es su desconocimiento de los límites. La mente humana se libera, el espíritu humano se libera. La libertad alcanzada con importantes costos (y precios) tanto sociales como individuales y tanto humanos como extrahumanos, "facultó" a las personas y a los líderes para resolver por fin la lucha de dominación sobre la naturaleza a favor del ser humano (se nos asevera repetidamente). Se declara el vencimiento de la naturaleza por las proezas del sistema (realmente subsistema) humano. Se declara el triunfo de la ciencia y la tecnología contra los avatares de lo natural. Se rompe la dependencia del hombre sobre los inefables del sino y del azar y, se declara el rompimiento con la historia: el tiempo pasado, pasado es, el futuro no está y el presente lo domina todo. Esto es libertad y, ésta libertad conlleva la rotura de los límites. Ahora el hombre puede volar y alcanzar otros mundos. Esta es una visión patrocinada por el sistema dominador, las realidades suelen ser bastante diferentes (¿extenuantes?)...

Todavía logramos tener cierta memoria histórica y simultáneamente una conciencia, esto hace que muchas personas puedan identificar que las promesas y ensoñaciones de progreso-desarrollo de los modelos aplicados queden así: siendo promesas y ensoñaciones. El mundo ha corrido vertiginosamente pero dentro de una carrera "loca y ciega" que además ha carecido de sentido: se ha corrido mucho pero no se sabe hacia qué lugar. La población humana mundial se ha incrementado violentamente mientras la calidad de vida general ha decaído plenamente. La distribución de la riqueza y de los poderes es cada vez más inequitativa con una elevadísima concentración de riqueza-poder en cada vez menos personas y una pobreza-miseria agobiante sobre enormes contingentes humanos. La injusticia es mayor y más compleja alcanzando lo que se denomina injusticia ambiental, de tan inmensa. El centro mundial se regodea en su inhumana abundancia mientras la periferia es más periférica y más "residual". El centro en su movimiento dinamista genera tremendas fuerzas tensoras y arrastra a la periferia que jamás podrá ponerse en igualdad de circunstancias. Las fuerzas centrífugas del poder producen su propia antítesis, fuerzas centrípetas de la periferia y el desequilibrio del sistema entre centro (más bien núcleo, y un núcleo muy duro, por momentos impenetrable) y periferia crea sostenidas fuerzas de fricción entre lo centrífugo y lo centrípeto de tal modo que la energía del sistema se gasta y pierde aumentando la entropía de los sistemas humanos o no humanos. Sin embargo, el proceso no cede y el sistema presiona más a los sistemas en general y a los ecosistemas en particular para mantener su cometido de movimiento perpetuo deseado, consumiendo, cual "agujero negro", todo lo que se pone a su alcance.

\section{El conocimiento no es el saber}

Toda una batalla teórica, ideológica y de otros fondos se ha dado alrededor del nacimiento (¿forzado?) de la sociedad del conocimiento pero no se habla igual, con la misma fuerza y tono abierto-demandante, de una sociedad del saber. La finalidad de la moda moderno/posmoderna del sistema dominador es la de ubicar a la sociedad globalizada y regida por el sistema de mercado en el conocimiento, 
no lo propone igualmente hacia el saber. Sí, una sociedad globalizada dada en el conocimiento pero sin llegar al saber.

No puede tender hacia el saber ya que toda vez alcanzada la muy utópica sociedad del saber (no muy promocionada por el sistema del poder) el propio saber y su imaginaria sociedad (más bien una "sociedad virtual o virtualizada", como anotaremos más adelante) tendrían que vérselas directamente contra el propio sistema en una desnuda guerra, ya no batalla, por el acopio del poder mismo y, esto el sistema dominador no lo va a permitir ni menos a promover: no cavará su propia sepultura; el sistema es necio, ciego y sordo pero no mentecato ni suicida. Se tendría una sociedad de conocedores pero inmunes a los "simples" brotes de sensibilidad humana; seres unidimensionales, homogéneos, estandarizados, desnaturalizados y sin alma/espíritu, dignos protagonistas de la sociedad del conocimiento que se plantea hoy, aunque por supuesto hay que señalar que hay otra sociedad del conocimiento posible, sí, igualmente utópica, pero muy distinta de la procreada y promovida por el sistema dominador hegemonista, la sociedad del conocimiento para la emancipación, que puede ser denominada de diferentes maneras.

Pero, cuando menos habría que ir un poco más allá. Conocimiento y saber solo son sinónimos en lo más general, en las particularidades se presentan sus diferencias que llegan a ser amplias y contundentes. Con ciertos manejos, digamos informativos, el conocimiento surge pero no de modo gratuito; para que emerja conocimiento de un hato informativo (el caso, acaso más generalmente dado, pero teniendo en cuenta que puede haber conocimiento generado de otras maneras, verbigracia: el dado por la genialidad de alguna o algunas personas extraordinarias que en un "golpe de luz" y/o en un momento de "iluminación" pueden crear un conocimiento sin la necesidad de tal hato informativo o incluso a pesar de él) deben correrse y/o cubrirse una serie de pasos que conforman el regular proceso del método (científico o de otras índoles). Dentro de este proceso, que además conlleva tiempo en el ínterin, las ideas y demás se consolidan, se da una maduración de la información implicada en su manejo más consciente y pensamos, más responsable. Bajo un manto permanente de los intereses y de las demás cualidades determinadas por la línea ideológica que se preestablece para generar un conocimiento, se va desarrollando el mismo conocimiento. Los recursos necesarios para esto pueden ser muy considerables en magnitudes y diversidad pero también pueden ser meramente escasos. Más tarde o temprano el conocimiento se crea, pero todo el procedimiento puede llegar a la falla y terminar mal, es decir, puede no alcanzar el objetivo/meta propuesto, asimismo puede resultar en un conocimiento equivocado, errado que traería ciertas consecuencias para el resto del conocimiento en general (recordemos el hecho histórico que por mucho tiempo dominó las mentes humanas de considerar a nuestro planeta como plano, las "evidencias" parecían indicar que la Tierra era plana, hasta que se demostró que no es tal).

El conocimiento así es una etapa superior al del acopio informativo y de él pueden ya extraerse nuevos materiales, nuevas informaciones y "productos". El saber es otra etapa y necesariamente una superior a la del conocimiento. Podemos conocer 
una cosa pero para llegar a saber tal cosa el camino puede ser tanto más largo como más laborioso. El conocimiento requiere para serlo, una auto aplicación sobre o de lo que se está conociendo, requiere su interiorización en el ámbito del que está conociendo. Cuando la información ha sido trabajada lo suficiente y cuando el que está realizando la labor se ha "adueñado" interiormente de las cosas y procesos, el conocimiento ha sido elaborado. En cambio, para que el conocimiento llegue a ser saber, se necesita que el conocimiento de que se trate se encuentre mucho más asimilado y probado/comprobado, que se haya instalado fuertemente en el que lo constituyó y/o reconoció y que cuando menos, se haya iniciado su distribución hacia el exterior o exteriores del modo más extenso. Por eso, el conocimiento ya montado en las alas de su propia divulgación y difusión llega a instaurarse/transformarse en saber, de ahí puede provenir en cierta medida la famosa sabiduría. En términos humanos, el saber, al menos hasta hoy es la cima del conocimiento, es el conocimiento más válido y valioso. El saber es la cúspide de la neguentropía. El conocimiento es una subfase de esa neguentropía.

El conocimiento generalmente se vende, se ofrece como una mercancía, el saber no puede ser comercializado, sería como vender seres humanos o almas/espíritus humanos: algo inaceptable (aunque suceda). Un tanto filosóficamente, el conocimiento se crea mientras que el saber se cría y recrea. El conocimiento puede ser inhumano, puede llegar a ser inhumano, el saber no. El saber forma parte de lo más humano de los seres humanos, es parte de lo más humanizado de todos nosotros, es una característica de la humanidad más humana, de su naturaleza más íntima, de su constitución más basal. El saber puede definir a la persona el conocimiento menos. El saber es la trascendencia del conocimiento.

Finalmente señalaremos que la ciencia se ha industrializado; el saber, sí es que realmente es saber, no puede industrializarse. Existen "fábricas" del conocimiento y "ciudades" del conocimiento (que siguen siendo "fábricas") donde ejércitos de trabajadores, hasta premios Nobel y así, se dedican en intensas jornadas a construir el conocimiento para captar el patentarlo bajo "marca registrada" y derivar potenciales ganancias económicas millonarias, y más poder. Pero, en cambio, no existen "fábricas" ni "ciudades" del saber. Hay empresas del conocimiento pero no las hay del saber. Sociedad del conocimiento no es lo mismo que industria del conocimiento y/o economía del conocimiento.

\section{La ciencia y la tecnología no cubren el conocimiento. Las tecnologías de la información y de la comunicación no son la ciencia, la tecnología ni el conocimiento}

Sin duda la ciencia y la tecnología son ahora unos entes que inclusive pueden presentarse como íconos de nuestra era. No puede ponerse en duda su enorme importancia y su alto impacto en la vida de (tal vez) la mayoría de la humanidad, solo habrá por ahí algunas personas y grupos que no se vean mayormente afectados por este poderoso dueto: la tecniciencia o tecnociencia. Si no fuera suficiente el involucramiento de la tecnociencia en prácticamente todos los quehaceres/asuntos humanos, está ahí la gran apología y presión que ejerce el 
propio sistema dominador/opresor para imponer semejante dueto e instalarlo e instaurarlo como principio, medio y fin del mismo sistema. Se hace una propaganda por todos lados y todos los medios y una publicidad que llega a los excesos, para adoctrinarnos en volver nuestras vidas "civilizadas" en unas dadas al uso y misma apología de la tecnociencia. Esto ha sido uno de los principales "éxitos" del sistema. Doquiera cualquier gente aparece por ahí "cantando las glorias" de la vida actual envuelta en las exquisiteces de la cómoda y entretenida existencia que brinda la tecnociencia en su raudo desarrollo de las últimas décadas (digamos, tal vez unos 50-70 años). Los líderes de muy distintas formaciones y representaciones, de todos los tipos y dimensiones avalan e igual entonan el "himno" de la derrota de la rudeza de la naturaleza para asegurarnos la bonanza y la vida casi "perfecta" del futuro gracias a la tecnociencia.

Aunque se nos presione para creer que las cosas son así, la realidad es suficientemente diferente y un mundo así está más bien en la imaginación y la fantasía, en la utopía y antiutopía que en los hechos. Si bien la tecnociencia ha modificado, en términos generales, al mundo, sus buenos éxitos se ven desencantados y rebasados por sus malos éxitos, lo que dice, en un balance (que quiere ser) imparcial, los beneficios aportados por la tecnociencia, hasta hoy, son menores que sus malos resultados, de tal modo que el mundo se encuentra todavía más desequilibrado que antes y la injusticia priva sobre la justicia, la pobreza/miseria es más amplia que la riqueza y los ecosistemas en todo el globo se encuentran bajo explotación insustentable. El desarrollo social se ha distanciado más de su realización y el ansiado progreso se encuentra todavía más lejos que antes, hasta resulta imposible.

En la pretendida sociedad del conocimiento, o sea, la sociedad actual, se ha establecido que la ciencia y la tecnología son el conocimiento pero, por supuesto que esto es una exageración. La tecnociencia es fuerte y cada vez más fuerte pero solamente es una parte del conocimiento. El conocimiento es mucho más extenso y diverso. "Simplemente" las conocidas como humanidades (filosofía, artes y demás) son conocimiento y no son ciencias. Pueden tener ciertos correlatos con la tecnología y quizás puedan crear y usar alguna tecnología pero no son su "razón de ser" definitiva ni definitoria. No nacieron de la tecnociencia ni se terminan en ella (cuando menos en los casos más generales).

El conocimiento científico es muy de un estilo de conocer. Se apega a principios y leyes que intentan ser lo más estrictas posibles. Cada vez se diseñan modos más específicos y estandarizados de hacer ciencia. Se avanza muy aceleradamente en el conocimiento científico pero se siguen arrastrando lastres del "pesado" pasado. Se siguen aplicando reglas/leyes que se suponen, al menos por cierto tiempo, inmutables. Algunas se han tomado como verdaderos "manantiales" del conocimiento pero jamás han sido ni han podido ser demostradas cuando una de las principales características del conocer científico es su plena e irrefutable demostración repetidamente. De nuevo, "simplemente" se las ha tomado como irrevocables por sí mismas, es decir, apodícticas. Una pauta epistemológica es mantener la duda, la duda "razonable" o "sana", pero otra pauta epistemológica es que una "verdad" científica lo es cuando el cuerpo de conocedores respectivo así 
lo asume; esto es hacer valer la "Ley (o Principio) de Autoridad", lo que sostiene que si lo dice la gente más reconocida del medio implicado, entonces "algo" se hace "Ley" científica. Esto último pondría y propondría a la ciencia más o menos en los mismos planos y contraluces que, digamos, las religiones o la religión en general, ya que si en las religiones es común el acceder al conocimiento por la revelación y la fe, la ciencia puesta en atmósferas así, también va caminando por los senderos de la propia fe: no resulta tan regalado que exista cuando menos una religión denominada cienciología o cientología que pacta sus cuestiones y asuntos con base a la ciencia en un periplo de no muy fácil entendimiento.

Por su parte la tecnología ha sido un tanto diferente en su trascurso histórico respecto al de la ciencia. La tecnología ha sido menos abordada desde lo teórico, aunque hay muy serios intentos de su estudio todavía ahora se encuentra en niveles menos explicados y conocidos que los "territorios" de la ciencia. Con su apéndice práctico sumamente desarrollado, "apabullantemente" desarrollado, su ramal teórico se ha subdesarrollado. La complejidad propia del material de estudio, la tecnología, ha operado para que esto suceda así.

La tecnología es mucho más abordable desde sus dimensiones materiales que incluso pueden "obedecer" a las ideas y deseos humanos, en cambio las dimensiones inmateriales de la tecnología no son tan "fácilmente" abordables y pueden hasta rebasar las cuestiones humanas que finalmente mostrarán sus propias limitaciones, así la tecnología puede estar en lo humano y puede ir más allá de lo humano puesto que llega a presentar cualidades y condiciones múltiplemente relacionadas, indistintas, irregulares e irreguladas, difusas, inexplicables, etcétera en función de su "esencia" que puede alcanzar las posibilidades de lo inasible e inabarcable, siendo que si esto resulta así para una persona más lo resulta para un grupo y mucho más para una sociedad. De todo esto, quizás, es de donde abreva por una parte la "adoración" por la tecnología, contrastada con la "negación" o rechazo y hasta menosprecio/desprecio y aún odio por la misma. Esta última condición se ve reforzada por el hecho de que pese a que podamos odiarla, de todos modos estamos inmersos en ella y (¿casi?) resulta imposible deshacerse de ella. Asimismo, interviene aquí la idea de lo nuevo. La tecnología hace pensar que al trabajarla se está produciendo "lo nuevo" y esto se traspasa directamente a nuestra mente para sentir ahora que lo tecnológico es lo nuevo y a la vez que lo nuevo es un mayor valor de las cosas, o sea, la tecnología ha contribuido mucho a aposentar a lo nuevo como un valor en sí mismo y además como fuente de valor, una forma de valorar.

La tecnología puede verse como tan antigua como el ser humano mismo, en este caso más bien la técnica, es decir, con algunas diferencias quizás mínimas, el ser humano ha producido tecnología desde siempre. Desde la tecnología más arcaica y/o "simple" hasta la más actual y/o compleja, digamos las complejas y complicadas tecnologías "de punta", de "última generación", del "futuro o mañana": el ser humano ha creado tecnología permanentemente. Del mismo modo histórico, el ser humano se ha vuelto dependiente de sus propias creaciones, lo que dice, genera tecnologías pero se ata a ellas y llega el momento en que no puede desligarse de sus mismas creaciones y éstas pueden llegar a dominarlo, como se 
presenta en el momento en vigor. De hecho, se produce tecnología pero ello conduce a buscar otras y más y más tecnología. La tecnología parecería "cobrar vida propia" y buscar su reproducción aún en contra de los intereses de sus propios productores, tal vez como un "Monstruo de Frankenstein": creación que se vuelve contra su creador.

La tecnología es indispensable, el ser humano no puede serlo sin ella (¿o sí?). La tecnología se posiciona como una necesidad verídica. Los excesos pueden presentarse y entonces se produce tecnología que ya no es necesaria y que solo afecta negativamente los sistemas humanos y no humanos, a los ecosistemas en general, ya que las tecnologías para ser empleadas, por fuerza requieren consumir materia y energía de los ecosistemas y a cambio sus productos resultan (en determinado caso) ser innecesarios y/o meramente suntuarios, un ejemplo: la extracción de oro y diamantes es una actividad de lo más cara en términos socioambientales, es altamente esquilmante del medio ecológico así como de las personas que tienen que hacerlo. Con un costo socioambiental demasiado alto, hasta impagable-irrecuperable, el oro y los diamantes extraídos pueden ir a parar, solamente, a las cajas de valores o de seguridad de los ricos y/o delincuentes o, para adornar el cuerpo o atuendo de los pudientes, un uso innecesario que incrementa el narcisismo de estas gentes.

La tecnología es una de las formas de interacción del ser humano con el medio, también es una de las formas de adaptación y trasformación del medio. La tecnología también se considera como una forma del conocimiento. Cierto conocimiento se vuelve tecnología y ésta puede producir nuevo conocimiento, se establece un cierto comportamiento más o menos cíclico. Sí, la tecnología implica conocimiento y puede generar más conocimiento, esto es cierto. Empero, la tecnología no puede tomarse como El Conocimiento, o sea, solamente es una parte del conocimiento e incluye un amplio espectro de cosas desconocidas, hay cuestiones de la tecnología que permanecen sin explicación. Así, la tecnología es una parte importante, muy importante del conocimiento pero no lo suplanta.

Integramos la ciencia con la tecnología y completamos nuestra aseveración expandiéndola: la ciencia y la tecnología son parte del conocimiento pero el conocimiento es mucho mayor que ellas, aún agregadas. Hay mucho conocimiento que no tiene que ver con la ciencia ni con la tecnología y que es factible que no tenga que ver con ellas jamás. Es posible que un conocimiento nunca llegue a producir ciencia ni tecnología alguna y de todos modos es conocimiento y puede ser uno muy bueno, válido y valioso, trascendente.

Por otra parte, con el repunte mayúsculo que la tecnología ha tenido en las últimas décadas, dejando un poco atrás a la ciencia para ponerse en el "Trono de la fama" mundial como el hito globalizado del momento, la elevada tendencia simplificante, reduccionista del sistema opresor ha logrado comprimir las cuestiones de la tecnología a su presentación más "familiar" de hoy: las tecnologías de la información y la comunicación, también conocidas como TICs. Se ha desatado una ola mundial por ellas con ellas en ellas y para ellas. Su popularización exponenciada y explotada al máximo, y hasta el hartazgo, ha dado vida a una nueva moda: ahora se llega a pensar y sentir que no se vive si uno no hace 
uso/aplicación de tales TICs. Se supone y presupone que todo tiene que ver con las TICs y hasta se anuncian sendos proyectos de "educación" alrededor del globo para adiestrar a toda la gente en las TICs y se llegan a plantear estrategias pedagógicas para capacitar a la gente en ellas y se intentan derivar teorías y postulados pedagógicos de ellas. Hay escuelas dedicadas a lograr la "competencia" en el uso/aplicación/perfeccionamiento de las TICs, lo cual lleva a producir y consumir más TICs.

Los tecnófilos se encuentran muy alegres de tal fenomenología y anuncian cada día los avances y meta-avances de la tecnología en general y de las TICs en particular; parecería que al fin alcanzaron el paraíso, que lograron penetrar al Nirvana tecnológico. De otro cuño y calado es la posición de los tecnófobos que lamentan fuertemente a lo que el mundo está llegando con una expansión colonizadora de la tecnología impresionante pero con una pérdida de lo más valioso que la humanidad posee en sí misma, es decir, su propia humanidad.

Las altas dosis de exposición a la ciencia y a la tecnología actuales y vigentes desde unas décadas atrás ha conducido a un cambio drástico de las sociedades, las comunidades y los individuos pero estos cambios solo son buenos en una parte menor, siendo más grande la cantidad y calidad de los cambios que, cuando menos hasta hoy, esas grandes dosis han conseguido en negativo: los beneficios han sido menores que los buenos resultados. Por ello nuestro mundo presente se encuentra ya no en una crisis cualquiera, una crisis más, tampoco en un periodo de crisis sino en un Estado y estado y además en un sistema (o cuasi sistema) de crisis, donde las crisis son muy numerosas a la vez que se imbrican las unas en las otras para obrar en la resultante de un mundo sumamente injusto y a todas luces insustentable, que se acerca peligrosamente más a los límites de la naturaleza para la sobrevivencia más elemental y vuelve a los seres, humanos o no, en máquinas y cosas, es el proceso de cosificación masiva donde las propias cosas ya no valen en sí mismas ni cuestan sino que solamente (re)presentan su valor de cambio en la maximizada presentación de un cosmos globalizador dado a lo decadente y propiciatorio de los conflictos más enconados en la lucha por el poder, el dominio, la riqueza y la hegemonía, pero dentro de unas batallas y finalmente guerra de todos contra todos iniciando por el enfrentamiento de los pocos que todo tienen contra los muchos que poco o nada tienen: caos, violencia, destrucción, insustentabilidad, deshumanización, desnaturalización.

En otra esfera, digamos y además si es posible separarle, las extralimitadas TICs se promueven por el sistema opresor como si fueran lo único y/o mejor que la humanidad tiene para continuar su existencia. Sin embargo, si la ciencia y la tecnología como tales no son ni pueden ser el conocimiento total y totalizante, menos las TICs pueden serlo, éstas son apenas un ramal de la tecnología y nada más. Es probable que en un tiempo más las TICs retomen su sitial en el contexto de lo humano y ambiental o socioambiental y sean reubicadas en el lugar que realmente les merece, como un componente más de la cultura humana, solamente un componente más del muy grande mosaico de la cultura. Asimismo, cabe la posibilidad de que el ingenio humano se rehabilite con las energías de la evolución natural y del núcleo central del espíritu más humano y bajo las operaciones del 
humanismo crítico preservador y contestador de la llana teoría crítica, las tendencias se vean modificadas y las ciencias, tecnologías y TICs pasen a ser materias secundarias delante de las cuestiones más meritorias de lo sustentable, de la vida sustentable basadas en la puesta en funcionamiento de la verdadera libertad humana, es decir, la libertad que se cobra únicamente a partir del Otro, del reconocimiento, del reconocimiento del Otro yendo más allá de lo complicado e insertando las complejidades en el ser/hacer de cada individuo y de los grupos hasta llegar a las sociedades y países o regiones. Estamos suponiendo una tesis que toma al Otro, que reconoce a La Otredad pero no se termina en asumir al Otro en las personas sino que se amplía hasta asegurar al resto de la naturaleza como el propio Otro. El respeto de La Otredad es la mejor versión de la libertad, de la libertad humana dentro de la sustentabilidad, misma que se retroalimenta del conocimiento para repuntar en la consecución de la necesaria gestación y gestión del saber ambiental. Lo que es una libertad estética para el conocimiento por imperativos no económicos ni veloces sino humildemente sencillos y por lo tanto bellos por sí, que podrán desplazarse amorosamente hacia la facultación/posibilidad del saber.

\section{La economía no es la vida y la economía del conocimiento no es la economía}

En su reduccionismo exacerbado el sistema opresor va simplificando las complejidades de la vida-existencia para poderlas manejar más a modo y para intentar controlarlas. Llega al caso de la sobresimplificación, o sea, la simplificación extrema en la que lo simplificado ya muy poco tiene que ver con lo original, las cualidades propias del material original han sido tan operadas que difícilmente pueden corresponderse con las condiciones de inicio y entonces, las personas y demás especies de la naturaleza en nuestro mundo han sido simplificadas y, sobresimplificadas en algunos casos. A la persona humana se le ha llegado a reducir hasta la elaboración ya no de una persona, de un ser pensante/sintiente sino que se ha creado la "imagen" de un modelo.

Para el sistema opresor las grandes mayorías humanas somos actualmente una cosa, hemos dejado de ser seres y más, hemos dejado de ser seres humanos, somos modelos. Todavía unos modelos experimentales, es decir, modelos con los que el sistema se encuentra ejercitándose para practicar sendos experimentos; se puede ver ahora el manejo de la genética donde se han abierto las puertas de posibilidad para manipular el nacimiento y la muerte. El sistema dominador ha presentado ya sus deseos de facturar nuevos seres con las características deseables para el mismo y ahí encontramos sus proyectos de eugenesia y eutanasia que bastante lejos quedan de las consideraciones más éticas y morales de la humanidad y de la humanidad histórica. La vida está siendo hoy patentada y registrada por los grupos de los poderes. La vida humana está siendo trabajada en las fábricas y ciudades de la ciencia/tecnología para poder construir en el lapso de tiempo más breve a los nuevos seres similares a las personas pero que ya son producidos por el sistema y para el sistema. No estamos hablando de proyectos de ciencia ficción, estamos hablando de proyectos reales y en curso actual que generarán nuevos seres de aspecto humano pero ya menos naturales que 
nosotros. Los clones humanos ya no son un "sueño" de la tecnociencia son ahora parte del proceso de desnaturalización y deshumanización del régimen dominador. Así el sistema podrá en un tiempo record disponer del "recurso humano" que necesita para sostenerse a perpetuidad sin tener que depender de las poblaciones humanas naturales tan "molestas".

Este es un proyecto de neopoblación para el otro proyecto mayor del sistema que es el de dominación total y absoluta por medio de la globalización mundial tan promocionada y perseguida (la que a su vez va ganando más adeptos). Si bien la globalización mundial es amplia y diversa, el motor y eje central de articulación de este modelo existencial del sistema dominador lo sigue siendo la materia económica. El proyecto globalizador es un nuevo modelo economicista caracterizado por la ascensión extrema de la importancia de la tecnociencia como la herramienta y objetivo/meta del propio sistema para conseguir la facturación de un nuevo modelo mundial de vida donde lo natural cada vez es menos y lo artificial es lo buscado, deseado e impuesto. Este modelo es diseñado y creado para acopiar todo y El Todo en nuestro mundo de tal manera que nada quede ya por fuera del poder centralizado hasta el absurdo y lo contraproducente. Un "nuevo orden mundial" se ha diseñado para que todo lo habido se encuentre controlado y pertenezca a los poderosos por medio de la maximización de la privatización de El Todo. La utopía capitalista neoliberalista reinante se está volviendo una realidad donde la propiedad privada será la rectora en todo lugar y momento. Ya nada será libre ni gratis, todo tendrá un costo y será propiedad de los grupos del poder glocal (global y local). Si bien por ahora esto todavía se encuentra en construcción, en un tiempo que al parecer puede ser muy cercano, el sistema dominador podrá disponer de todo lo material y hasta lo inmaterial en nuestro mundo. El sistema corriendo por todas partes y copándolo todo, muy velozmente se está adueñando de todos los ecosistemas y hasta de las mentes y almas/espíritus de la gente. No está dejando nada por fuera de su dominio y se avizora la gestación definitiva de la oligarquía mundializada por medio del proyecto de globalización.

El instrumento o medio óptimo del sistema para lograr tal y tan espeluznante fenómeno glocal mundializado es la economía y la estructura u organización para hacerlo es el mercado global. La economía desde hace mucho tiempo dejó de ser una cualidad de las culturas, igualmente la economía dejó de ser subsidiaria de la política para ser ahora la política una subsidiaria de la economía. De hecho la tendencia mundial es la de hacer de la economía La Política, es decir, la regla de la existencia toda. El rasero medidor/resolutor de todo. Casi no van quedando instancias y/o sustancias donde la economía no tenga que ver y/o donde la economía no sea la posición medular. La persona humana se califica o descalifica por la vía económica; el colmo es que la propia vida, la vida como fenómeno hasta hoy exclusivo de nuestro planeta, igualmente se encuentra siendo cooptada por los procedimientos de tasación y los avalúos del mercado haciendo de la vida, no otra cosa que una mercancía más en el mercado y "libre" mercado de la comercialización más llana, sea ésta legal o ilegal.

La economía está decidiendo todo y su posición es absolutamente central. Nada puede competir hoy con el rubro económico de tal suerte que si uno es y si uno 
existe es solamente a través de una ubicación económica, más específicamente economicista. Parecería cuestión de paradoja, de oxímoron pero no es así: la ciencia y la tecnología no alcanzan a explicar ni tan solo a describir cómo puede ser que la economía se encuentre absorbiéndolo todo y tomando el lugar de Decisor Final (¿fatal?), incluso suplantando la posición/función que anteriormente ocupaba Dios o los dioses de las diferentes religiones glocales. Empero, aunque muy "avanzado" el proyecto mundial de estupidización de la gente, todavía tenemos la cualidad pensante y podemos darnos cuenta y anunciar al sistema dominador que la vida es mucho más que números en las tablas y modelos economicistas. Que la economía si bien puede ser una necesidad para la gestión de los grupos humanos e individuos, solamente es una parte de El Todo y no puede reemplazarlo ni será bueno que lo haga. La economía es un componente de la cultura pero no es más importante que la cultura, menos lo es que el ser humano: jamás podrá ser más importante que la vida ni puede ocupar el lugar central que la vida es. La economía no es la vida ni puede ni debe serlo.

La propia naturaleza tiene su economía y la ejerce. De ahí el enorme e impactante proceso evolutivo de millones de años en nuestro mundo y de millones y millones de años en el universo. Digamos, la economía de la naturaleza es la termodinámica, mientras que el lenguaje de la naturaleza es la ecología. Cuando la economía y el lenguaje de la naturaleza se conjugan emerge de ahí el proceso evolutivo, la evolución, el fenómeno natural (de origen) que llevó a nuestro planeta a servir de criadero y a la explosión hasta sumamente estética de la vida: a la génesis de la vida. El proceso muy largo en el tiempo que por medio de la evolución ha creado la vida con todas sus innumerables especies y manifestaciones (muchas de ambas desconocidas hasta el presente) ha sido un ejemplo de la aplicación adecuada de la norma que establece el buen manejo y la vigilancia de la calidad en la operación de la cantidad (economía natural, economía ecológica). Regla natural que no es reconocida ni aceptada por el régimen explotador del sistema opresor y que una y otra vez es rota por el mismo con las enormes consecuencias negativas que conocemos (y otras más que desconocemos y pueden ser peores aún). La naturaleza tiene sus propias economías (remarcamos) y el sistema dominador se centra en lo económico, por lo tanto no puede desdeñarse simplemente a la cuestión económica, pero sí debe ser acotada, delimitada y maniobrada benignamente para empatar la evolución natural con la evolución humana histórica. Sin embargo, retomar a la dimensión económica en su más justa y ambiental o socioambiental medida es lo pertinente desde la perspectiva de la sustentabilidad, si queremos hacer participar en todo esto a la sustentabilidad. Simultáneamente tenemos que entender y comprender que la economía no se puede simplificar reduccionistamente a la economía del conocimiento como se ha pretendido en los últimos años. Al lanzar el sistema dominador su novedad de la creación o existencia de la sociedad del conocimiento linealmente la ha hecho paralela a la economía del conocimiento asumiendo que al ser lo central en todos sus modelos impuestos el aspecto económico, entonces, dentro de la sociedad del conocimiento también lo toral es la economía, en este caso más especialmente la economía del conocimiento. Con ello lo que se pretende es instaurar un conocimiento de la economía totalmente acorde con el 
modelo de existencia economicista. Si el conocimiento será eje rector de la producción y reproducción social a la vez requerirá, según el sistema opresor, de su propia línea económica totalmente a su favor excluyente.

La noción de la economía del conocimiento es bastante reciente, quizás tenga alrededor de unos 20 años, pero aún siendo así de nueva ha marcado ya su huella en el orbe y en las maneras de hacer y ser. La economía del conocimiento supone igual interés de todos por ella y no hace distinción entre gente de países ricos y gente de países pobres. Supone alta homogeneidad y supone igualmente que todos deben ponerla en acción y sin cuestionar nada sobre ella. Pero esto es otra de las grandes falacias del sistema opresor ya que si es tanto un medio como un fin del propio sistema, son las minorías las que han escuchado hablar de ella y las que le dan mayor o menor importancia. Las grandes mayorías permanecen ajenas a este hito de la economía del conocimiento para la sociedad del conocimiento. Mientras grandes grupos poblacionales en todo el mundo sobreviven muy apenas, debatiéndose en los entuertos y violencias de la pobreza y la miseria donde digamos, la mitad de la población mundial no tiene un presente, se le ha eliminado su pasado y se le niega un futuro, es increíblemente pretensioso/arrogante imponerle su adscripción a la economía y sociedad del conocimiento cuando ellos mismos no figuran, no cuentan, no existen para el sistema que exige la creación de tal economía y sociedad sencillamente ficticias.

Todavía así, una fracción de la propia fracción enterada de la economía del conocimiento, es decir, una subfracción, aboga por la instauración, instrumentación e institución de la economía del conocimiento suponiendo que el conocimiento es hoy la "moneda de cambio" única y que si un país o cultura desea proseguir, no le queda otra más que adosarse a la economía del conocimiento puesto que de no hacerlo quedará fuera del sistema globalizador y será caldo de cultivo para su subdesarrollo. Es, digamos, la nueva Ley: o se es parte de la economía del conocimiento o se está sentenciado (sin juicio ni nada) a desaparecer. Los derechos, sean del tipo que sean, son secundarios y muy secundarios en el modelo opresor. Millones y millones de personas carecen de vivienda, de trabajo, de atención para la salud, de condiciones para su educación, de libertad, de paz, etcétera pero a cambio deben ser "autómatas replicantes" predispuestos a pertenecer a la sociedad del conocimiento y practicar "entusiastamente" la economía del conocimiento. Si esto no nos resulta un sinsentido inmoral y aberrante entonces el sistema opresor nos habrá vencido ya.

Entusiastas de la educación se han dado y se dan a la tarea de proponer formas y medios "adecuados y eficaces" para que los sistemas educativos logren permear los distintos estratos sociales y las diferentes sociedades, colectivos e individuos y hacer una realidad el proyecto de la economía del conocimiento. Se habla de la necesidad de educar en todos los niveles de la educación sistematizada para la economía y sociedad del conocimiento, que unos pocos también llaman sociedad del saber (incrementando el error denominativo y de fondo). Se plantea como necesidad verdadera el que el subsistema de la educación superior se "modernice" aceleradamente para conseguir estudiantes "aptos", "calificados" para la economía y sociedad del conocimiento. Tal vez, los planteles educativos, en 
general y, en lo particular los de educación superior deberían ser los primeros en marcar el alto a este fenómeno impuesto. En lugar de estar "inventando" los modos de hacer realidad estos proyectos del imperialismo actual, si son centros de la educación tendrían la obligación más humana de aplicar el análisis crítico, la teoría crítica más elemental y mediante otra aplicación del humanismo crítico deberían antes de proceder a sumarse a semejantes entes del dominio opresor, someter a fuerte revisión crítica y propositiva tanto a la economía como a la sociedad del conocimiento. Tal debería ser su primera tarea, resaltamos. Estudiar muy arduamente a tales entes y someterles a juicio y prueba y, más, cuando se está tratando del presente y del futuro no solo de la humanidad completa sino del destino de los ecosistemas y del resto del mundo natural.

Desde otro encuadre, tal vez especial, la economía es una rama de la ecología; la ecología es el manejo de la casa y la economía solamente es la administración de la casa, por ello es una rama y no el todo de la ecología, digamos para el caso que estamos planteando. Solo en sistemas degenerados o que tienden a la degeneración una parte del sistema puede tomar el lugar del todo. Una característica propia de los buenos sistemas es que están constituidos por elementos y factores, o sea, componentes diversos. En los sistemas la diversidad es una buena cualidad en lo general. En los sistemas biológicos esta cualidad es todavía más importante, valiosa y benigna. Parte del buen estado y buen funcionamiento de un sistema viene dado por su diversidad. La norma general es: a mayor diversidad sistémica, mejor funcionamiento del sistema. Así el buen funcionamiento de un sistema y su soporte en el tiempo y espacio, lo que dice, su sustentabilidad, dependen en franca medida de su diversidad. Cuando una de las partes del sistema somete a las otras y en el caso extremo suspende a las otras quedando como el todo, la diversidad se habrá perdido y el sistema se habrá degenerado. Un sistema degenerado es un sistema malhadado.

Quizás de manera retórica esto es lo que puede estar sucediendo. La economía del conocimiento quiere suplantar a la economía del manejo de la casa (la ecología), mientras que la sociedad del conocimiento quiere suplantar a la sociedad glocal. Cuando esto sea un hecho, el sistema opresor podrá declararse finalmente vencedor y las personas habremos dejado de ser personas para ser objetos de consumo-consumismo: modernos esclavos del sistema. Del mismo modo, la economía del conocimiento no puede suplantar a toda la economía.

\section{La sociedad no es una empresa y el mundo no es un mercado}

La empresa lo es para los negocios, la sociedad es mucho más que negocios. Mientras más humanos somos menos nos preocupamos y ocupamos de los negocios. Los negocios son para algunas personas y grupos no para toda la gente: no todos somos negociantes así como no todos profesamos una religión o la misma religión. Los negocios son una forma sofisticada, aunque igualmente impiadosa, de la guerra y, afortunadamente no todos somos guerreros ni tenemos que serlo. Los negocios son parte de la vida pero la vida no es un negocio, es mucho más que y suficientemente distinto de ello. 
Antes la economía era la ciencia o el conocimiento de los medios mientras que la política era la materia de los fines. Al cabo del tiempo y por la implantación del sistema opresor esta relación o correlación sociocultural histórica se trastocó y hoy resulta al contrario, es decir, la economía es la materia de los fines y la política es, de algún modo, la cuestión de los medios. En el presente la política ya solamente es reconocida para ser aplicada directa e indirectamente a lo económico: si la política ha de ser es por medio de su reconocimiento como la política económica y la economía política es el tronco común de la existencia de los individuos y colectivos humanos. La empresa cobra las dimensiones locales, nacionales, regionales, internacionales y hasta mundiales. Las Mega Empresas han construido un nuevo mundo, mundo afín para el manejo sobre-extendido de sus intereses y, sus poderes son tan fuertes y grandes que han logrado ponerse por delante de los quehaceres y retos políticos (y de los otros de cualquier clase). Las formas de gobierno se han doblegado ante el poder del economicismo y las empresas dictan sus lineamientos a los gobiernos glocales. La mayoría de los países o Estadosnación llegan a depender ampliamente de las imposiciones de las empresas. El capital se instala como neo-religión y con su permanente poderío se ha trasladado a ocupar el sitio del gobierno. Sí, el capital gobierna desde hace mucho tiempo y la mayoría de los países se encuentran cada vez más débiles delante de los mandatos del poderoso capital glocal.

Las elecciones para los principales puestos de gobierno quedan recortadas por los designios del poder capitalista y casi no llega a ocupar un puesto de gobierno nacional una persona que no haya sido "aprobada" (si no es que directamente impuesta) por el sistema opresor. Aquella persona que logra el gobierno de un país sin haber sido el elegido por el sistema capitalista se enfrentará a situaciones extremas donde hasta puede ser que todo el país deba pagar semejante "desobediencia", "atrevimiento". Pero estas son unas cuantas excepciones, la regla es la de gobiernos comprometidos con el capital y/o gobiernos comparsa o cortejo del capital. Con tal regla operando constantemente, los países han dejado de ser sociedades y culturas para ser operados como empresas y la gente ya no es ciudadano de un país sino un empresario o un empleado/subempleado de una empresa o un desempleado. Hemos dejado de ser personas y personas humanas para pasar a tomar una ubicación en términos laborales: empresario, socio, accionista, empleado, subempleado, desempleado, jubilado, pensionado; o sea, el economicismo en plena marcha ejecutoria.

La empresa se tiende sobre el mundo y lo coopta, lo satura y sobresatura con emisiones de negocios donde la calidad de la vida depende de la posición económica laxamente (y laxantemente) y los demás componentes de la existencia, hasta las cuestiones más íntimas del ser se las ubica en terrenos secundarios y se las tasa hasta donde se le es factible a los medios del sistema impuesto. Todo se compra, todo se vende, todo se ve como negociable. Los principios, los valores, los ideales, los sueños y anhelos se toman como negociables y parte del mundo de los negocios. La educación se negocia y se abre una gran línea de educación para los negocios siendo, por ejemplo, que para nuestra región, Latinoamérica, la educación superior se ve ampliamente dirigida al campo de los negocios con por lo menos un tercio de la matrícula escolar cubierta por las licenciaturas de 
administración de empresas y afines, completado el fenómeno por la presencia de escuelas profesionalizantes dadas exclusivamente para el área de los negocios/empresas. La educación en sus sistemas nacionales se va abriendo considerablemente a suministrar el "capital humano" como el "producto" común de la aplicación de la perspectiva economicista del mundo de los negocios en la que la persona no se define como tal sino como "recurso humano", o sea, otro ente económico más que da por "producto" final un "capital humano".

Hoy se dice que estamos en una era o momento conocido como postindustrial, se habla de que vivimos en el postindustrialismo, lo que dice, que se ha rebosado la era industrial. En el ínterin industrial se hablaba de la producción y el consumo así como de la competencia en los mercados, digamos de forma general. Ahora, en el postindustrialismo las cosas cambian y se habla de productividad, consumismo y competitividad del mercado, es decir, los hitos del industrialismo se han exponenciado, se han recrudecido y se asume al proceso globalizador como panacea para alcanzar el éxito, la felicidad, el desarrollo y hasta el progreso (hacemos hincapié en que el desarrollo no necesariamente es lo mismo que el progreso): con la aplicación de más ciencia y más tecnología el sistema dominante asegura que se lograrán vencer los numerosos y complejos escollos y finalmente en el futuro (que más bien cae en el futurismo más positivista o neopositivista) se tendrá una vida de alta calidad donde los problemas de pobreza, miseria, injusticia podrán ya ser resueltos tecnocientíficamente y de modo definitivo. Pero esto no es más que la añeja utopía de la sociedad mundial/global "feliz" que si bien es utópica de por sí, no se le ve la cualidad de ser una utopía realizable, alcanzable, al menos no para el gran bloque de las mayorías humanas y tampoco con los niveles de degradación negativa de los ecosistemas, base única e irremplazable del soporte de toda la actividad y vida humanas, ecosistemas que van menguando sus capacidades en lugar de mejorarlas con su evolución natural impedida por las intervenciones explotativas humanas exageradas (asociadas al dispendio) que rompen los ciclos de función y recuperación de la naturaleza y agotan/agostan el medio desbordando las reglas, hasta hoy inmanejables para el ser humano, de la ecología más fundamental.

Al violentar las leyes de la naturaleza el ser humano se está jugando el destino de la población humana. Un destino que el sistema dominante piensa debe ser el de la famosa Aldea Global en la que no hay ya fronteras y en la que la productividad/consumismo hacen las veces de Definición de la existencia tanto humana como del resto del orbe. Misma Aldea Global donde rige centralmente una sola cultura, la occidental, desplazando o excluyendo a las demás culturas y la probable emergencia de nuevas culturas. Una cultura occidental de tipo estadunidense matizada con componentes europeos que dan por resultado el suponer que las demás culturas alrededor del globo son, de algún modo, desechables puesto que la cultura occidental estadunidense/europea vale por todas ellas y vale más que todas ellas: es la cultura del Imperio, sin duda. La ascensión de la cultura occidental como la única es el triunfo del modelo globalizador mundial e implica la construcción más "exitosa" de la "autopista" más modernista para cursar por ella los enormes y pomposos vehículos del grandioso desarrollo, anunciado y publicitado por los medios del sistema dominante. 
Autopista por la que igual correrán los productos del mundo de los negocios así como las bases más sólidas para fabricar el mundo/universo del mercado mismamente único, es decir, el mercado global, el sueño/ensueño y anhelo máximo del sistema economicista. Así, el sistema más sistematizado aun y sumamente tecnologizado estará en condiciones de campear irrestrictamente y de imponerse absolutistamente, lo que se traduce directamente en la creación del "mercado ideal" del capitalismo neoliberal: el mundo completo vuelto un mercado único y excluyente donde el Imperio reinará hegemónicamente y el valor superior lo es el económico y no más, junto a la consideración del valor de cambio como el valor rector de toda la Experiencia Humana, para que el ser humano sea "medido" y significado por su poder de compra/venta y/o su poder de participación como negociante y/o empresario. El Imperio del poder que exige más poder y el reinado del monopolio. El poder monopólico en su mayor potencial avasallador.

Este sueño/paraíso del hipercapitalismo se torna una pesadilla/infierno para miles de millones de personas y no se diga para el resto del coto de la naturaleza, partes ecosistémicas tanto bióticas como abióticas que para el sistema imperante no dejan de ser reemplazables, sustituibles, como ha procedido desde siempre. No obstante, esto es una falacia prácticamente atroz y desde el humanismo crítico es, inaceptable, intolerable. El mundo es el ámbito de la vida y de lo vivo. El mundo es el hábitat del alma/espíritu humano. El mundo es diverso y bello. Es, hasta el día de hoy, el solo lugar donde es posible la existencia humana y de lo humano. Considerar al mundo como el mercado máximo/único es una reducción grosera, antinatural, inhumana, insustentable, violenta y probablemente mortal.

El ser humano es solo una especie de las miles o millones que habitan el planeta y de las que se cuentan en muchos más millones que lo han habitado. ¿Qué faculta al ser humano para considerarse el decisor final y plantarse como "El Elegido" para determinar el destino no solo de la humanidad sino del planeta y de la vida? ¿Qué faculta al sistema opresor para decidir que todo debe hacerse negocio y que el mundo no es más que un gigante mercado? ¿Qué ley determina que la vida misma sea una mercancía? ¿Qué ley dicta que el mercado es la forma en que se debe vivir? ¿Quién es el sabio conocedor o conocedor sabio que puede establecer perfectamente el valor en dinero de una especie biológica, y con reglas absolutamente científicas? Para nosotros y desde la teoría crítica de intención más sana el mundo es muchísimo más que un mercado y los valores del mundo económico son mucho menores a los valores humanos más históricos, sean universales o no tanto: el mundo no es un mercado y el mercado no es el mundo. Igualmente: la sociedad no es una empresa y la empresa no es la sociedad.

\section{Las sociedades reales y las virtuales (las presentes y las imaginadas). Toda sociedad es una sociedad del conocimiento}

Cada vez las sociedades se van haciendo más virtuales y cada vez, más rápidamente. Pero el fenómeno es muy amplio. La sociedad se virtualiza pero simultáneamente se escinde más ya que solamente una parte de ella se ve más intervenida por la virtualización mientras una gran porción social sigue quedando 
al margen de éste proceso vertiginoso. Por supuesto que estamos "acomodando" en la virtualización a otros entes vigentes como la: digitalización, matematización, robotización-automatización, hipercomunicación, hiperinformación; en fin, la tecnologización de la vida, digamos, también el Imperio de la electrónica se le podría llamar y puede lanzarse, quizás la denominación de "existencia multimedia". Cuando menos en nuestra región geocultural, América Latina gran parte de la población (que puede llegar a ser la mayoría) está fuera de los procesos de "alfabetización digital" y otros más que se han desatado por el mundo. Esto puede ser todavía más drástico en vastas áreas de África y Asia. De hecho, hasta el momento el proceso general de virtualización que estamos denominando así, solamente funciona y quizás "muy bien" en Europa, Norteamérica y una porción reducida de Asia. La porción más amplia del mundo permanece "analfabeta digital" (y "analfabeta científica") aunque no podemos considerarla ajena a estos procesos pero siendo que hasta la propia Organización de las Naciones Unidas (denominación hasta cierto punto eufemística) reconoce que la mitad de la población mundial actual, verbigracia, jamás ha hecho 0 recibido una llamada telefónica, la situación está muy clara...

El proceso es más grande, complejo y diverso de lo que pudiera creerse a simple vista. Una situación y/o problema es que la gente se vea presionada para virtualizarse, es decir, para operar los instrumentos electrónicos disponibles y otra situación o problema es que su propia vida/existencia, su propio ser íntimo, su conciencia y su alma igualmente se han ido virtualizando junto con sus relaciones con otras personas y con el medio, hasta con la naturaleza y con los inmateriales (digamos en este caso como ejemplo sus relaciones con Dios o con los dioses que mantiene mediante alguna religión o creencia o sistema ideológico, entre otros ítems del cosmos que podemos apuntar como metafísicos o escatológicos, de la psicoesfera). Estas cuestiones exceden considerablemente las posibilidades del presente escrito y solo podemos tocarlas muy someramente.

La virtualización es un imperativo actual del sistema dominante que al mismo tiempo que promueve por todos los medios su aplicación masiva exige que las personas se conecten directamente al sistema operativo que se va expandiendo raudamente en el mundo. Aquí surgen varios problemas. Uno es el "analfabetismo digital" presente y muy amplio, otro es que pese a los grandes embates del sistema dominante, la disponibilidad de los equipos para realizar la virtualización global está todavía muy remota de conseguir sus propósitos, o sea, solamente poca gente a nivel mundial tiene acceso abierto y en "buenas condiciones" a los equipos. El equipamiento glocal es muy inferior al requerido para darse el proceso de globalización y además, la tremenda obsolescencia propia y hasta autoprogramada de tales equipos hace que cuando se ha avanzado en ciertos niveles, muchos equipos pasan a ser una nueva chatarra-desecho. Esta suerte de nudo gordiano no se ha resuelto y no se observa que en el plazo corto pueda ser resuelto. Pero a esto se le puede agregar que la distribución mundial del equipamiento es tan mala como la correspondiente a la de las riquezas y pobrezas y, a la de las responsabilidades y consecuencias de la aplicación de los modelos existenciales impuestos por el sistema opresor glocal. Todo esto no es poco decir, llega a plantear un problema tan severo como el de la utópica realización del 
mundo en la consecución de la felicidad, mito histórico que permanece irresuelto, mismo mito que ha quedado más vedado/bloqueado mientras más insustentable se hace el paradigma vuelto ya paradogma de la gobernancia del orbe por medio del sistema capitalista. Sistema antinatural que por su misma cualidad contraria al mundo natural es insustentable, se diga lo que se diga y se reforme como se reforme. Los reformismos de los modelos capitalistas de vida solamente han generado mayores distancias entre grupos humanos y entre éstos y la naturaleza externa al ser humano, acompañadas de una extrapolación de las diferencias negativas entre unos y otros, diferencias que se ven explotadas por el sistema que discrimina e impide la vinculación sustentable entre humanos y entre humanos y naturaleza extrahumana.

Por otra parte pero no en desconexión de lo anterior, la virtualización de la vida es real, aunque suene a oxímoron o paradoja. Cuando la gente es cosificada y reducida a sus dimensiones mínimas no solo pierde contacto con la realidad sino que ella misma comienza a trastornarse y va tornándose en un ente con nuevas características que tienden a lo virtual. La realidad es trabajada por el sistema opresor para dirigir la existencia misma de las poblaciones. Semejante trabajo comporta un desgaste de la propia realidad hasta su simplificación o incluso su sobresimplificación para abatir las complejidades del ser y del ser humano. El desgaste ocurre a la vez sobre la persona y la va determinando; parte principal del determinismo impuesto se encamina y puede terminar en la producción de elementos y factores que virtualizan tanto a la realidad como a las personas. El ser humano va dejando de ser y se va acondicionando como un nuevo ente virtual mucho más manipulable para sostener los designios del sistema opresor. Parte de la virtualización del ser es hacerlo un ente biológico sesgado hacia las apariencias. El proceso puede llegar al punto en el que el ser ya no lo es sino solamente es un conjunto de componentes que en demasiados casos no tiende al orden sino más bien al desorden mismo que es nutrido por el caos general imperante en el orbe. Sometida la persona a vastos procesos de violencia física y mental en variadas presentaciones y niveles que pueden observarse, digamos, a partir de las crisis repetitivas y constantes que le aquejan cotidianamente y asociado esto al proceso de estupidización masiva gestado y operado por el sistema dominante, la persona humana pierde sus cualidades más definitorias y pasa a ser persona "simple" y después se torna en cosa. La inteligencia propia de la persona en lugar de cultivarse es atacada por las fuerzas del sistema y va menguando hasta obtener sujetos que más bien son ahora objetos.

La inteligencia humana es quizás la más importante cualidad diferenciadora de nuestra especie respecto a las demás, sin embargo y como puede ser constatado por nosotros mismos en nuestro medio inmediato y también en el más mediato, la persona común, el ser humano regular va simplificando sus formas y se va sujetando a las imposiciones del medio impuesto. Mucha gente ya no lucha contra este proceso, hay gente que se ha rendido y puede cotejarse cómo tanto en sus ideas como en sus acciones y actitudes va tendiendo a acoplarse a lo preestablecido por el sistema para doblegarse y "participar" en el fenómeno grupal e individual de despersonalización dado por la fuerza opresora de la globalización economicista. Vamos menguando nuestras cualidades más personales e íntimas 
para pasar a simular que somos lo que el sistema quiere y lograr con ello protegernos de las consecuencias o bien, intentar sacar alguna supuesta "ventaja" respecto a los demás para ubicarnos, de ser posible en una situación menos expuesta a los riesgos y amenazas dentro del crudo mundo hipercapitalista.

Nos vamos deshumanizando y simultáneamente nos desnaturalizamos, vamos dejando de ser humanos para maquinizarnos y digitalizarnos, somos seres mutantes que vamos virando de seres pensantes a seres virtuales constituyentes de algún algoritmo matemático aplicado electrónicamente a la naciente nueva sociedad global dirigida hacia la sociedad del conocimiento practicante de la economía del conocimiento. Ahora ya no somos sino que simulamos ser, ya no pensamos si no actuamos sin pensar, ya no somos responsables ni tenemos que serlo. Ya no nos ocupamos de ser tampoco nos preocupamos del deber ser sino que nos dejamos engullir por el sistema y sus promesas (amenazas y riesgos incluidos) y buscando un sucedáneo a la realidad que antes éramos nos preocupamos y ocupamos de cubrir las apariencias para "demostrar" lo que somos y valemos, igualmente nos vestimos del color de la moda del momento para mimetizarnos con el medio y formar parte de él para apacentarnos en el seno del sistema impuesto y disfrutar, de ser posible, de los placeres de la vida tecnologizada actual y prepararnos a los placeres que siguen de acuerdo al futuro que la tecnociencia ha publicitado que serán los disponibles y los que harán las vidas futuras unas llenas de "felicidad" con el mundo ya globalizado y siendo la sociedad la propia del conocimiento, otro "Mundo Feliz" de Huxley. Seres mutantes somos, consciente o inconscientemente. Seres virtuales más que seres biológicos reales: mucha gente hoy prefiere vivir en el mundo virtual dispuesto por los aparatos electrónicos más novedosos que darse cuenta de la realidad que impera fuera del "cosmos" electrónico de unas vidas sobrellevadas en las caras alas de la tecnociencia más de última generación. Vida artificial y vida virtual.

Empero, no podemos dejar de anotar y resaltar que la existencia virtual que no se empata con la vida real y se aparta cada vez más de la vida más natural se basa en un error de concepción fundamental: supone que la sociedad debe ser la sociedad del conocimiento, es decir, prescribe deterministamente que el mundo tiene que ser el dado por el conocimiento, donde la vida se da y persigue en todo momento y lugar la producción de conocimiento y el ser de la persona está definido por una plataforma de conocimiento que en el caso más general, es un conocimiento científico y tecnológico excluyente de otros conocimientos y del saber o de otros saberes distintos. Aquí el conocimiento es la "regla de oro" y el valor más absoluto (más bien absolutista) y al ser fuertemente excluyente deja por fuera y tiende a desaparecer otras formas de ser, de pensar, de actuar, de conocer y saber. Pero el error más específicamente es considerar que el destino de la humanidad está regido por el conocimiento y por tanto, la única sociedad factible es la sociedad del conocimiento "funcionalizada" por la economía del conocimiento. El error consiste en la necia ceguera real, no virtual de suponer que solo la sociedad puede devenir a otra "mejor" por medio del conocimiento denegando que otras maneras de hacer sociedad son posibles y existen ya y han existido desde hace mucho tiempo. 
El conocimiento y el saber más serios e históricos nos muestran y enseñan que toda sociedad es una sociedad del conocimiento. Sí, si una sociedad en realidad lo es, entonces conlleva en su seno más constituyente y vivo el conocimiento así como el saber. Hasta el día de hoy un grupo humano conformado ya como sociedad mantiene y sostiene como parte intrínseca y medular tanto al conocimiento como al saber. No podemos decir que propios ya que más bien las sociedades son híbridas, es decir, no son excepcionalmente autónomas, no hay sociedades "islas" independientes de todo contacto con el resto del mundo, lo que hay es la generación de sociedades que se elaboran y reelaboran una y otra vez tomando y retomando, adecuando y readecuando sus nexos con el resto de lo existente y de lo que ha existido. La existencia de una sociedad implica un largo y duro proceso de intercambio con el medio, más bien en el ambiente y ello implica el intercambio con otros grupos y otras historias.

No hay una sociedad del conocimiento dada por el proceso de globalización economicista, acaso habrá una sociedad de la información y de todos modos habría que demostrarlo. No hay una sociedad del conocimiento única y excluyente sino lo que hay es todo un mosaico/conjunto histórico de sociedades del conocimiento y, esto no puede ser eliminado por decreto del sistema dominante, de la historia de la humanidad glocal. El conocimiento tiene su lugar en toda sociedad pero solamente es un componente de la cultura, el conocimiento no puede tomar el lugar de la cultura. No todo consiste en conocimiento y no todo depende del conocimiento. El conocimiento no es omnipotente, cuando menos no hasta ahora y menos si solo se trata del conocimiento científico y tecnológico. Es bueno y es valioso pero la vida depende de otros tópicos más y en determinadas condiciones, esos tópicos son más importantes que el mero conocimiento (como los principios y valores más legítimos, en su caso). El ser humano y la vida y la calidad de vida del ser humano pueden depender más de otros ítems en ciertos momentos y situaciones que del conocimiento. Finalmente mencionaremos que a pesar de que el conocimiento viene desde que el ser humano existe, es más lo que desconocemos que lo que conocemos tanto de la vida como del universo, resulta muy presuntuoso/soberbio suponer que lo poco que conocemos de todo, acerca de todo es lo que determine el valor de las cosas, de la vida y de las personas, individual y/o socialmente. Esta soberbia/presunción es una manifestación más que de una sociedad del conocimiento o de la información, de un capitalismo del conocimiento que igual puede "fabricarse" a través de un capitalismo de la información, primero.

\section{La sociedad del conocimiento dentro de la sociedad del desconocimiento y del reconocimiento}

La sociedad del conocimiento que realmente es en el presente la sociedad de la información (acaso) no deja de ser una propuesta interesante además de importante. Como propuesta tiene sus dimensiones para reflexionar sobre ella pero como imposición del sistema es muy otra cuestión. De alguna manera se podría asumir que estamos hasta cierto punto dentro de una sociedad de la información que asimismo, puede mirarse como un paso previo hacia una 
sociedad del conocimiento. La sociedad del conocimiento es una oportunidad, vista como una propuesta, para replantear el presente y el futuro de la sociedad donde el conocimiento sea reubicado en el plano dimensional que le corresponde pero en el que debe vigilarse muy estrechamente tanto sus postulados más meritorios desde lo sustentable, humano, ambiental así como sus medios, objetivos, metas, espacios y tiempos coligados a la noble/honesta observación de sus límites y puntos de inflexión y de equilibrio socioambiental.

Antes que nada la sociedad del conocimiento si se logra, debe ser una sociedad incluyente, sustentable, humanizada, ambientalizada. Einstein, uno de los científicos más prestigiados y reconocidos de la historia dijo algo así: antes que ser hombres de ciencia deberíamos ser hombres. Nos aunamos a este enunciado magistral y bellamente humano, belleza que emerge de su propia simplicidad (aunque contenga un sesgo sexista, quizás). Antes de pretender crear una sociedad fundada en el conocimiento primero tenemos que generar una sociedad, planteamiento elemental pero que el sistema opresor no toma en cuenta y tiende a violentar cotidianamente mediante su proceder despótico y destructor impositivo. A través de medios violentos y no violentos el sistema imperante ha destrozado a la humanidad, ha roto las sociedades y ha partido el ser del propio ser humano.

El sistema opresor ha escindido a las sociedades tanto como a los individuos para gestar las condiciones de producción y reproducción que le son a modo. Lo ha hecho abierta y veladamente y no se ha detenido en ningún momento ni terreno. Empero, ahora pretende dar lugar a una nueva sociedad, la del conocimiento basada en la economía del conocimiento y movilizada por la sociedad de la información. No sabemos si logrará instalar tal sociedad de conocedores pero sí sabemos que tal sociedad será insustentable (y en consecuencia inviable) si no opera primero y después sobre bases más justas que a la vez respeten tanto las reglas más históricas de la ética universal y las de la moral más elemental tanto como las reglas inviolables de la naturaleza, las reglas, digamos, ecológicas. Sin embargo, si procede del mismo modo en que lo ha hecho por siglos, el sistema no podrá dar lugar a una sociedad más humanizada/ambientalizada por más conocimiento que contenga.

El sistema está olvidando que además de los valores de la economía del conocimiento y de la ciencia, existen los valores humanos y los ecológico/ambientales y mientras no se procure el equiparamiento o empate más sano y trascendente entre estos sistemas valorales, todo esfuerzo puede resultar en la nada o algo peor. Por ejemplo: el Estado de Bienestar proveniente del propio sistema dominante terminó produciendo mayor malestar que bienestar, el desarrollo producido fue sumamente parcial y el progreso se imposibilitó más.

Mientras sea el mercado glocal el eje trasversal de la existencia humana y mientras la vida y el conocimiento en dicho sistema no posean mayor valor que el de una mercancía y por lo tanto el mayor valor para tal sistema no sea otro que el valor de cambio, la sociedad del conocimiento será otro paradigma trastornado a paradogma glocal pero tan relleno de insuficiencias, errores y desigualdades/desequilibrios que tal sociedad del conocer no podrá mantenerse 
más que por la vía directa de las armas para golpear individuos, grupos y sociedades, física y sicológicamente: dictadura y fascismo.

El sistema dominante ha olvidado las cualidades más humanas del conocimiento. $\mathrm{Ha}$ sostenido que el conocimiento se puede crear sin tomar en cuenta las meras características más humanas de las personas que lo generan. El conocimiento como mercancía es un error más del sistema, es además, uno de sus errores más grandes. El conocimiento/mercancía es un conocimiento frío, hueco, ralo, partido, deshumanizado, desnaturalizado, quizás hasta inmoral, y no podemos dejar fuera el conocimiento "ilegal" o como se le quiera denominar, un conocimiento que solo es creado para malas aplicaciones, para aplicaciones "del mal" como el dado a generar armas del mayor potencial destructivo, dispositivos para "digitalizar/maquinizar" a las personas y otros seres, incluyendo la "fabricación" de nuevos seres; métodos de ocultación, mentira/engaño/simulación malsana, tortura y desaparición de personas, métodos electrónico/computacionales, cibernético/informáticos para el crimen, etcétera.

Pero todavía más. El sistema pretende producir una sociedad del conocimiento (con todos sus malos contenidos y consecuencias y, claro, pensando también en que posea algunas buenas cualidades) a partir de la sociedad actual que es una sociedad del desconocimiento y esto dicho por lo menos desde dos vértices distintos (sería posible desgranar más, por supuesto): la sociedad actual es una sociedad del desconocimiento y, la misma está basada en el desconocimiento. Lo que queremos decir es lo siguiente.

Nuestra sociedad es una del desconocimiento. Como mencionamos antes, el conocimiento que tenemos sobre El Todo es meramente minúsculo, es elemental, resulta superficial y mínimo además de relativo (hay un gran relativismo) delante del enorme desconocimiento que tenemos en realidad, digamos, de la misma realidad, material e inmaterial. La mayoría de nuestras ciencias son jóvenes y algunas apenas son "bebés". Incluso hay ciencias que apenas se están proponiendo como tales y otras tantas todavía no alcanzan el reconocimiento como ciencia (pese a que pueden ser tan añejas como otras calificadas como ciencias donde el juego de los poderes es lo que determina qué es ciencia y qué no lo es). Lo que dice: nuestro conocimiento científico es de lo más limitado y es el conocimiento científico al que privilegia el sistema dominante. Pero otros conocimientos, ya no científicos, pueden encontrarse en iguales o peores condiciones, es decir, pueden estar aún más retrasados en sus avances positivos e incluso el sistema dominante los ha combatido y tratado de eliminar como sucede con la filosofía, verbigracia. Digamos que se avanza (i?) en un sentido sobre el conocimiento (en general, científico o no) pero se obstaculiza y hasta pretende eliminar otros conocimientos. El balance es extraño y cuesta elaborarlo (imparcialmente) pero las realidades nos dicen que no es un balance satisfactorio, no cuando menos para las grandes mayorías humanas y para el resto de elementos y factores ecosistémicos (bióticos y abióticos): tenemos una crisis ecosistémica grave, tal vez la crisis ecosistémica más importante de la historia humana que además, es la expresión de la que probablemente sea la crisis más fuerte de la humanidad de la humanidad neta. 
El conocimiento se trasmite por muy distintas vías y se puede decir que permanentemente, pero la sociedad ha dispuesto a los sistemas educativos como los más aptos y los más expresos para trasmitir el conocimiento. Los sistemas educativos glocales revisten una significancia elevada para el sistema de dominio y lanza sendos proyectos "educativos" estandarizados para homologar la trasmisión del conocimiento y para homogenizar la educación completa. Las formas de trasmisión o traspaso del conocimiento de los sitios de su creación hacia los sitios de su instalación, 0 sea, las poblaciones glocales están construyendo un nuevo monopolio al respecto. El sistema no solo va buscando la estandarización del conocimiento y de su traspaso a las sociedades sino que está generando las condiciones para monopolizar su trasmisión hacia las personas. Este monopolio no puede ser sustentable como cualquier otro fenómeno monopolizador y en el caso del conocimiento la situación se ve agudizada cuando sabemos que hoy el conocimiento se ha aposentado en ubicaciones privadas, en empresas y ciudades del conocimiento que "patentan" e imprimen "marca registrada" a todo el conocimiento que sale de sus "fábricas del conocimiento". La industrialización del conocimiento no es una utopía sino un hecho. Los sistemas educativos glocales se están reformulando en términos economicistas de un monopolio globalizado y resulta un hecho álgido que las instalaciones educativas han sido defenestradas de su sitial histórico como generadoras del conocimiento y, les están dejando en la práctica, solamente la función de su trasmisión.

Esto aplica directamente otra norma del sistema opresor: el conocimiento así como la educación no pueden ser ya puestos a la disposición del pueblo, no pueden ser ya populares sino un conocimiento/educación de tipo privado establecido lineal y fielmente para sostener al sistema dominante que le da origen y lo gobierna bajo directrices de negocios. Por todos lados se puede observar como las instituciones públicas se van debilitando y desapareciendo para dejar el espacio/tiempo a las privadas que contienen directivas considerablemente ajenas a las necesidades de las grandes mayorías humanas, con una base medular que toma a la persona ya no como ciudadano sino como un cliente, que ya no estima a la persona como persona humana o sujeto sino como una cosa, un objeto y que aplica directamente las reglas de trasmisión del conocimiento y de la educación en general no para formar seres humanos positivos sino para deformarlos al modo de clientes y manejarlos como "exactos" asuntos de negocios y "precisos" "puntos de venta". En tal sistema los gobiernos glocales ya no deben preocuparse por el suministro de bienes y servicios a la población puesto que ya están en expedición todo tipo de empresas privadas que a la vez pueden operar por la moda del sistema (cadenas) de "franquicias" para hacer grandes negocios con tales bienes y servicios y todo cuesta y se valora en expresiones, digamos, de dinero sin entrar en las cuentas ni mínimamente el verdadero costo socioambiental de tales bienes y servicios. En los rubros educativos podemos ver que cada vez más van apareciendo alrededor del mundo unidades de las empresas/universidades más "prestigiosas" del orbe en los formatos del sistema por franquicias, en una "macdonalización" (ese modo tan "especial" e industrializado de hacer negocios en serie que tiene como "modelo" a seguir a la famosa cadena de hamburgueserías alrededor del mundo con sus "comederos" que cada vez están más distantes de 
ser restaurantes) de los sistemas educativos glocales y con la perversión de lo que la educación y el conocimiento son, no digamos ya de lo que deberían ser.

La "macdonalización" de la educación y del conocimiento es más vasta y compleja de lo que se pudiera suponer sin más. Implica la simplificación y la sobresimplificación de sus, digamos, contenidos. El conocimiento de que tratan es sencillamente el conocimiento "útil", si un conocimiento no tiene una aplicación rápida para producir expedita y abundante ganancia, no se le considerará en el sistema. La educación está abiertamente para incrementar la fuerza de los valores economicistas y deshacerse de los demás valores que pueden ser contrarios (y de facto lo son) al paradogma impuesto. Así, en lo más replicado sobre la educación se establece lo que debe "enseñarse" en los sistemas educativos glocales a todos los niveles educativos, desde párvulos hasta la educación de tercer nivel. Por ejemplo, se impone que todo el mundo debe estudiar la lengua inglesa ya que es el lenguaje del Imperio. Se impone un recorte de las líneas de la Historia, de la Ética y del Civismo. Se impone la estructura del Liderazgo y de la educación por Competencias. Se impone la educación por medio de las TICs. Se impone que toda educación debe ser "optimizada" como un negocio. Se impone la ley inquebrantable de tomar al mercado como el regidor glocal único. Entre muchas otras imposiciones... La macdonalización de la educación, del conocimiento y hasta de la vida misma es un sueño/ensueño del sistema dominador y ha castigado ya fuertemente a diferentes bloques humanos y no humanos. Con semejante modo de producir conocimiento y con semejante manera de "educar" lo que se tiene en este momento es un proceso bruto de adoctrinamiento férreo sobre las poblaciones humanas para impedir la respuesta de las mismas y para medrar los focos de resistencia contra el modelo neoliberal.

La gente se encuentra más debilitada y es más dependiente todavía, por si fuera poco, se encuentra más temerosa y se siente expuesta a un "no sé qué" que le convida mayores resquemores de amenazas latentes y de riesgos inminentes para forjar al paralelo de la sociedad del conocimiento pretendida, otras sociedades más reales que son la sociedad del riesgo y la sociedad del temor. Y otra más, que quizás sea menos conocida, la sociedad de la estupidización, puesto que con la creación así del conocimiento y de la educación en nuestra época, la gente cada vez tiene menos elementos para su defensa del sistema opresor y sus cualidades de inteligencia y de otros tipos pero de los más entrañablemente humanos van siendo combatidos y abatidos. En el inicio de la sociedad del conocimiento la gente se encuentra, en general, dentro de un proceso recargado de estupidización y vemos que hay personas que ya no pueden pensar con cierta soltura y vemos que a los educandos cada vez les cuesta más realmente aprender algo, no se diga ya acceder al saber.

Los niveles de ignorancia se han incrementado y de ahí ha ido surgiendo otra sociedad, la "sociedad del ascenso de la insignificancia" en la que se ha perdido o se está perdiendo el valor central de la priorización, elemento/factor primordial de un modelo existencial sustentable, ambientalizado. En dicha sociedad lo trivial es el corazón de la acción y del sentido, se dota de sentido principal a lo que en realidad apenas merece ser tomado en cuenta. Es lo que variados autores 
presentan como la enorme pérdida de sentido de la sociedad actual y también reportan como "el sentido del sinsentido", igualmente "la razón de la sinrazón" vigentes. La gente se vacía y se extasía con apenas unas migajas y detesta o rechaza las cosas más relevantes para acomodarse placenteramente y disfrutar de lo más llano y banal, de lo más simple y fútil que determina a final de cuentas la atracción de la gente por las cosas más simplistas y la vida se hace una existencia simplona, se hace un derroche y un espectáculo para todos, y la vida se olvida de la propia vida para "encantarse" por las tecnologías más llamativas del momento incluso antes de que salgan al mercado y para regodearse en un mundo vacuo dado a la diversión y al entretenimiento mientras los "think tanks" planean y deciden el secuestro del mundo en el crimen del siglo.

En el sistema actual muy cursado por componentes caóticos el todo puede tomar cada parte pero igualmente cada parte puede tomar el todo. Al no haber prioridades dentro del desorden propio del sistema en su alta inestabilidad y contingencia, en determinada condición una parte puede ser tan "valiosa" como cualquier otra. Así, por ejemplo, el sucedáneo deportivo que hace las veces de "magnífica" anestesia para grandes grupos humanos, a la vez que funciona como excelente fuente de ganancias para el sistema del poder, es surtido abundante y constantemente para mantener atrapados a los fanáticos del deporte y a otros individuos "despistados" o así, sin importar en realidad la calidad del deporte y sin tomar en cuenta o sin enterarse las personas que el deporte en nuestra era es uno de tipo industrial, sí, lo que se tiene es un deporte industrializado donde el carácter deportivo, el llamado "espíritu deportivo" brilla más por su ausencia y añoranza que por su presencia. El deporte no es más una actividad para "mantener sano cuerpo y alma" sino una mercancía en el mercado mundial, en el mundo de los negocios, la "Galaxia Pecuniaria" o "Universo Crematístico", y donde los deportistas son más objetos que sujetos y se compran, venden, alquilan y se prestan como si de meros objetos se tratara para ser explotados hasta dar de sí (lo mismo está sucediendo con los científicos y creadores de neotecnologías). La gente vive (¿o sobrevive?) entusiasmada/alucinada por cada evento deportivo, incluso por cada partido de algún deporte y no se diga de la esperanza (y fe) hasta religiosa desatada todos los fines de semana para vigilar afiebradamente y asistir a toda la oferta de deportes con los que "nutre" su perforada/contaminada alma natural y nativa hasta el hartazgo más pasmoso para enfrentar como una pesadilla el lunes de la nueva semana; semana en la que permanecerá hambriento por el confite extraordinario que le deparará el próximo fin de semana en un festín incomparable de deportes y más deportes y consumo y más consumo. Este comportamiento "normal" de muchas y muchas personas se vuelve una conducta de tan repetida $\mathrm{y}$, supone el desplazamiento de cuestiones mucho más importantes/trascendentes a planos dramáticamente secundarios de importancia. El deporte cumple con creces las funciones que el sistema opresor le ha destinado. Forma parte del proyecto de estupidización glocal. El otro deporte, el que se preocupa y ocupa de la gente permanece muy a la sombra del deporte industrializado y tiende a desaparecer, acosado, por ejemplo, por la gran oferta y uso de los juegos de video, un substituto modernista del deporte, digámosle. 
Bajo tales circunstancias, cuestiones de mayor envergadura social son minimizadas y devoradas/ocultadas por toda la propaganda y publicidad dadas en el deporte industrializado. Nadie quiere "perder" el tiempo con asuntos, cuestiones y problemas sociales, políticos, culturales, ecológicos: les resultan "aburridos", chocantes. En cambio, nadie quiere perderse ni un segundo de tal partido o competencia deportiva. No hay prioridades en el mundo del economicismo: anotar un gol o realizar cualquier anotación en un encuentro deportivo es mucho más importante para millones de personas que resolver o atender un problema político. Los deportistas (industrializados) se vuelven "astros" dentro del mundillo deportivista industrializado. La gente les idolatra, los torna de anónimos a ídolos y llegan a cobrar las "glorias" de ser ubicados como "héroes patrios" o "héroes nacionales". Adquieren mayor popularidad que los políticos, gobernantes, los empresarios o las figuras religiosas. La gente puede estar muy al tanto de quién es "el Rey Pelé" o Rafael Nadal/Roger Federer pero no guardan el mismo tanto acerca de quién es Ban Ki-Moon o Cristina F. de Kirchner.

El sistema puede proclamar que estamos yendo hacia la sociedad del conocimiento pero igualmente nos encontramos y nos dirigimos hacia una sociedad globalizada del desconocimiento, mínimamente tomando al desconocimiento como ignorancia o una forma de ser de la ignorancia. La ignorancia cunde por todos lados y niveles. Hay una expansión de la ignorancia, una "metástasis" social de la ignorancia. Esto visto en lo general, pero asimismo aparece en nuestro opacado horizonte nuboso una nueva ignorancia, producto directo del modelo opresor. Se puede apuntar que nos situamos en una sociedad de la nueva ignorancia. Hay una nueva ignorancia en el horizonte de millones de personas, algo que más o menos se correspondería con lo que se ha denominado analfabetismo digital. Gente que tenía un buen nivel cultural, de momento se topó de frente $y$ violentamente con toda una nueva parafernalia electrónica/computacional/informática o como se le quiera llamar, que la ha relegado, desplazado, presionado, bloqueado y hasta eliminado de sus quehaceres comunes llegando al extravío de sus puestos laborales (y otros) e incluso causándole daños morales, emocionales, espirituales con una pérdida que puede ser grave de su propia identidad al sentirse "inútiles" delante de la enorme tecnologización de la vida, cuando menos en muchos lugares. Sí, el sistema ha fabricado nuevos analfabetas y nuevos ignorantes: una nueva ignorancia.

Pero la problemática va más allá de esto. La sociedad vigente es una que tiene por norma el desconocimiento general y el desconocimiento del Otro en particular. Que es nuestro segundo punto en este ítem.

La persona humana está constituida por un yo básicamente propio pero éste no surge de la nada ni por generación espontánea, emerge de un medio social y a través de un tiempo mayor o menor. Somos el resultado de un transcurso tanto natural como intervenido por el resto de las personas. No somos entes aislados sino somos células vivas integrantes del famoso y muy manido "tejido social". Nos guste o no y nos demos cuenta o no somos resultado de un proceso socializado y nuestro yo personal, si bien es "propiamente nuestro" se ha ido generando por razón del intercambio con el medio, tanto el inmediato como el mediato. Entonces, 
de una manera muy resumida, el yo que portamos está constituido por otros yos que representan al resto del medio, lo que dice, somos solamente por medio de los demás. Es la intervención de los demás la que aporta nuestro yo íntimo. Nuestro yo es la combinatoria de los demás, de los otros, La Otredad nos constituye a cada uno de nosotros. El Otro es el personaje central del proceso mediante el cual el yo moral llega a serlo. Habrá por ahí unas muy pocas excepciones a esta regla socio-individual de integración del yo, pero en la muy vasta mayoría así sucede: en el yo propio tenemos la presencia y la representación de muchos otros yos correspondientes al Otro. Una gran parte de nuestro yo personal está formado por los otros y en algunos casos la fracción dada por los demás dentro de una persona es tan amplia que se cae en casos patológicos donde el sujeto individual carece de una reformulación más propia y deviene en una despersonalización haciendo totalmente dependiente al sujeto del resto del medio, reculando éste en situaciones de pérdida lamentable de su identidad más íntima, junto a un extravío de su conciencia, muy seguramente.

El sistema dominante está construido para las competencias y la más alta competitividad. Todos compiten y tienen que competir contra todos y por todo y, todo el tiempo. No hay treguas ni descansos, el proceso es hirientemente sostenido, constante y velozmente acelerado. La sociedad se ha ido desintegrando en un extenso proceso de atomización. Se privilegia al individuo, los grupos se desgastan y se intenta su ruptura definitiva, el individualismo se maneja como un valor importante para el modelo existencial presente (y futuro). El individualismo más egocéntrico, egoísta, ególatra es el promovido por el sistema dominante. Así se procura las bases necesarias que le aseguren la mayor batalla campal permanente de todos contra todos: la solidaridad es contraria al sistema. La solidaridad es vector de sustentabilidad y lo insustentable es parte de la naturaleza del modelo explotador dominante. Siendo que el sistema procura por todos los medios (y muy en ello los medios masivos de información/comunicación) el enfrentamiento eterno contra los demás, contra los otros para conseguir su vencimiento, su derrota y hacer del "éxito" la meta de una vida solitaria en el mundillo del egocentrismo atomizador, simboliza/codifica el "triunfo" por sobre el resto de las personas con la subida al sitial del "Líder" al vencedor de las múltiples contiendas y por lo tanto hace o impone el carácter de "inferiores" (también "perdedores") a los que no pudieron conseguir tal sede de privilegio.

Este sistema funciona mediante privilegios y son los privilegiados los que pueden "ser", los demás tiene que ser "determinados" por los "vencedores" o "líderes". Así, el sujeto no podrá jamás aceptar que su yo interior esté constituido por los otros y se establece un doble problema: el individualismo ultra-egotista dado por el sistema dominante hace que la persona tenga que rechazar a los demás, que deba observar a los otros como meros contendientes, como sus enemigos (y hasta en ello, a la elemental naturaleza exterior al ser humano) y por lo tanto no aceptará que su yo íntimo quede constituido también por la intervención de sus "odiados y odiosos" rivales. El Otro solo representa amenazas y riesgos y por lo tanto debe ser vencido y si es posible eliminado; se tiende a construir la mayor distancia posible entre el sujeto y los otros. Pero por otra parte, su yo interno igualmente se ve tensado y llega a romperse dando por resultado la división 
interior del sujeto y lo que se tiene es un individuo roto y confundido en su mismo seno más privado/íntimo. Se aleja de sí mismo. La conjugación de ambos procesos determina lo que hoy tenemos: atomización social e individuos desequilibrados, confundidos, enfermos: sociedad debilitada y personas debilitadas. Una sociedad que ha sido descrita como zoociedad.

En este modelo reinante la persona no se reconoce a sí misma y tampoco reconoce a los demás. El reconocimiento del otro, de los otros queda práctica e ideológicamente vedado, sin embargo, el paradogma establecido, dentro de uno de sus numerosos contrapunteos que alcanzan hasta lo absurdo (insistimos), en otro sentido es uno que se mueve y se alimenta por el reconocimiento.

La sociedad de la información junto a su secuela, la pretendida sociedad del conocimiento, entabla una batalla gruesa entre el conocimiento, el desconocimiento y el reconocimiento, una batalla de lo más compleja y complicada que victimiza generalmente a las poblaciones sin distinción. Para debilitar a las personas y sus asociaciones (momentáneas o más consolidadas) y hacerlas más dependientes y avocadas a las imposiciones del sistema opresor ataca a los colectivos y rompe el fuero íntimo de las personas, refrendamos. Logra instalar el miedo/temor en el ambiente de tal modo que genera la lucha de todos contra todos en la diaria actuación de la mayor competitividad nunca antes vista.

Para afectar a los sujetos por una lado golpea hasta obtener la buscada respuesta de volver a cada uno de nosotros un "competidor extremo" y dispuesto a todo (o casi a todo) para conseguir algo o por lo menos para sobrevivir en el medio convertido en "campo de combate". El Otro, la Otredad ya no es nuestra aliada en esta lucha aciaga y cada miembro de la Otredad es resumido a su papel de rival, de adversario, de enemigo que nos amenaza y se significa como un riesgo que debemos eliminar. El sistema ha conseguido, entonces, su objetivo en este sentido: romper los ligamentos y cementantes sociales y apartarnos de los demás hasta llegar a oponernos a ellos. Esto implica una doble "victoria" del sistema opresor sobre nosotros: ha conseguido así que desconozcamos (en el sentido del rechazo) a la sociedad, a la Otredad, al mismo tiempo que ha logrado empañar y retorcer negativamente tanto los vínculos socioculturales que ahora observamos a la misma Otredad como nuestro enemigo, con ello ha alcanzado a forjar en nuestro seno íntimo el desconocimiento del otro, de los otros y hasta del ambiente.

Quebrantando los lazos sociales y nuestra mera intimidad personal el sistema consigue lo que persigue: primero desconocernos a nosotros mismos, o sea, que uno mismo se desconozca para luego pasar a desconocer a los demás (o viceversa) para que en un rejuego de las cosas, el desconocimiento de los otros sea igualmente un vector muy eficaz y eficiente para lograr el desconocimiento de lo que uno mismo es y debe ser. El desconocimiento de uno mismo llega al tope inmoral e inaceptable por lo tanto, de ya no permitirnos el re-conocimiento de uno mismo lo cual cuela sendos trastornos de la personalidad y de la identidad: seres humanos rotos, difusos, confundidos, extraviados es el resultado de esto.

El asunto es más agudo y sostenido de tal manera que el sistema en contraparte impone otra de sus reglas o "verdades": si uno no alcanza el reconocimiento de los 
demás, no es ni existe. Pero aquí no se trata del reconocimiento humano, del reconocimiento socializado y ambientalizado, se trata del reconocimiento regido y medido por el hito y código modernista/economicista del "éxito" sin digamos, "apellido". El reconocimiento válido para el sistema dominante es el dado u obtenido mediante el éxito renutrido en términos de fama, bulla, popularidad, notoriedad acompañados de novedad. Solo los seres exitosos gastan el reconocimiento del medio y solo el éxito es el que se otorga a través del prestigio, la fama y otros componentes de una "bien" (re)presentada parafernalia, digamos del poder, la calidad de estar vivo y formar parte del propio sistema, lo cual significa, asimismo, tanto ser como existir. Los no exitosos pueden ser desechados y son considerados como inútiles para el sistema y son elementos residuales de los que debe disponerse incluso sin tener que entrar en cuestiones morales ni menos de la ética. Son "periferia" del sistema y entonces son fácilmente reemplazables dado su muy bajo valor (o nulo valor) para el sistema valoral economicista (que por su misma naturaleza contiene fuertes constituyentes inhumanos). La transformación de las personas a casos y cosas sin valor utilitarista es otro de los sonados "triunfos" del sistema opresor que así va consiguiendo su doble propósito de desconocimiento/reconocimiento y de conocimiento/desconocimiento.

La persona humana necesita conocimiento pero al mismo nivel requiere de reconocimiento. Entelequia. El sistema dominante desconoce la entelequia necesaria entre el conocimiento y el reconocimiento y la produce o quiere producir y reproducir mediante la aplicación de más ciencia y más tecnología. La sustituye y prostituye con todo tipo de sucedáneos/placebos y elementos/factores virtualizados y virtualizantes. No tiene capacidad para dar una respuesta sostenible-sustentable que atienda y entienda tal entelequia. Toma al conocimiento como finalidad pero lo desconoce como medio, asume el reconocimiento social en términos crematísticos perturbados y perturbadores yendo más lejos al querer imponer al conocimiento como la panacea única histórica que resolverá todos los vericuetos de la sociedad y del mundo. El totalitarismo aberrante del sistema dominante termina en un totalitarismo de la tecnociencia más deshumanizada y deshumanizante.

La sociedad del conocimiento no se puede valer por sí misma para autoreconocerse y menos para brindar el reconocimiento social humanizado/ambientalizado que la gente necesita y llega a exigir, por lo tanto, el sistema carece de la estructura más elemental de auto-gestión crítica que le dote de las posibilidades de romper los obstáculos que ella misma se ha impuesto. Según su propia fórmula y la aplicación de la misma, su conocimiento solo ha ido produciendo mayor desconocimiento y su conocimiento ha generado solamente reconocimiento del humano pero en formas virtuales que han virtualizado a las personas y al resto de la naturaleza en el orbe. Nuevamente recurriendo a Einstein podemos anotar otra de sus acotaciones, que más o menos dice: no podemos esperar que las cosas cambien cuando seguimos haciéndolas del mismo modo. A lo que completamos un poco con la nota marxista que señala que el modelo capitalista por sus mismas propiedades no será el que procure la modificación 
medular del propio sistema del capitalismo. Tomamos estas dos ideas para realizar nuestra salida del presente escrito.

El sistema opresor no va a brindar ni tan solo las más simples oportunidades para que el mundo pase de una sociedad de la información (y quiera fabricar una sociedad mundial del conocimiento) hacia una sociedad sustentable, humanizada, consciente, responsable, sana, trascendente, naturalizada y ambientalizada. Nos queda solamente a nosotros mismos el intentar y buscar las sendas del cambio toral de este modelo opresor/explotador/agotador a otro creado y recreado en la solidaridad y el conocimiento vuelto saber en general y saber ambientalizado en particular. Reconociendo que el conocimiento si lo es, entonces es un bien de todos y para todos, y potencialmente, bienestar para el ecosistema integral Planeta Tierra, nuestra hermosa casa sideral. Proponiendo que la elaboración del conocimiento está en todos nosotros y que su crianza para llegar a ser saber es ocupación y derecho/responsabilidad de todas-todos, misma crianza del saber que en sí misma lleva el redimensionamiento de lo que el conocimiento es, su valor y su (re)ubicación más acertada en el entramado sociocultural glocal.

\section{Bibliografía}

Araújo, J. 2004. La Ecología. Maeva. Madrid.

Agudelo C., C. A. 2009. ¿Qué tan lejos estamos de la sociedad del conocimiento? Revista de Salud Pública. Vol. 11. No. 4. Universidad Nacional de Colombia. Bogotá.

Balderas, R. 2009. ¿Sociedad de la información o sociedad del conocimiento? El Cotidiano. Vol. 158. Universidad Autónoma Metropolitana. Azcapotzalco. México.

Bauman, Z. 2005. Ética posmoderna. Siglo XXI. Argentina.

Bauman, Z. 2007. Miedo líquido. La sociedad contemporánea y sus temores. Paidós. México.

Benjamín, W. 2008. Tesis sobre la historia y otros fragmentos. Ítaca/UACM. México. 
Binimelis E., H. 2010. Hacia una sociedad del conocimiento como emancipación: una mirada desde la teoría crítica. Argumentos. Vol. 23. No. 62. Universidad Autónoma Metropolitana. Xochimilco. México.

Casas, M. 2005. Nueva universidad ante la sociedad del conocimiento. Revista de Universidad y Sociedad del Conocimiento. Vol. 2. No. 2. Universidad Abierta de Cataluña. España.

Castells, M. 2001. La Galaxia Internet. Areté. Madrid.

Castoriadis, C. 1998. El ascenso de la insignificancia. Cátedra. Madrid.

Chávez L., E. 2010. La técnica, el gólem y la custodia. Revista Investigación Científica. Año 6. No. 1. Universidad Autónoma de Zacatecas. México.

Dussel, E. 1998. Ética de la liberación en la edad de la globalización y de la exclusión. Trotta. Madrid.

Fisichella, D. 2002. Dinero y democracia. De la antigua Grecia a la economía global. Tusquets. Barcelona.

Fuente (de la), J. R. y E. Egron-Polak. 2010. La construcción de la sociedad global del conocimiento: El cambio sistémico e institucional. Universidades. Vol. LX. No. 45. Unión de Universidades de América Latina y el Caribe. D. F. México.

García, R. 2006. Sistemas complejos. Conceptos, métodos y fundamentación epistemológica de la investigación interdisciplinaria. Gedisa. Barcelona.

García C., N. 2007. Lectores, espectadores e internautas. Gedisa. Barcelona.

García L., A. y J. M. Moreno J. 2008. Economía y democracia en la sociedad del conocimiento. Estudios en Economía Aplicada. Vol. 26. No. 2. Asociación de Economía Aplicada. España.

González S., O. 2008. Complejidad, instituciones y antropología. Reflexiones sobre los límites del conocimiento antropológico en la sociedad del conocimiento. Desacatos. No. 28. Centro de Investigaciones y Estudios Superiores en Antropología Social. D. F. México.

Habermas, J. 2000. Teoría y praxis. Estudios de filosofía social. Tecnos. Madrid.

Held, D. 2002. Modelos de democracia. Alianza. Madrid.

Herrera G., M. y P. Castón. B. 2003. Las políticas sociales en las sociedades complejas. Ariel. Barcelona.

Lamo de E., E. 2001. La reforma de la universidad en la sociedad del conocimiento. Revista Española de Investigaciones Sociológicas. No. 93. Centro de Investigaciones Sociológicas. Madrid.

López C., M. 2008. Formación humana y sociedad del conocimiento: de la ambigüedad a la complejidad. Revista Internacional de Ciencias Sociales y Humanidades. SOCIOTAM. Vol. XVIII. No. 1. Universidad Autónoma de Tamaulipas. México. 
Mattelart, A. 2000. Historia de la utopía planetaria. De la ciudad profética a la sociedad global. Paidós. Barcelona.

Morin, E. 2003. El método V. la humanidad de la humanidad. La identidad humana. Cátedra. Madrid.

Offe, C. 1990. Contradicciones en el Estado de Bienestar. Alianza. Madrid.

Olivé, L. 2008. La ciencia y la tecnología en la sociedad del conocimiento. FCE. México.

Rivera de la R., J. y L. Rodríguez M. 2008. La sociedad del re-conocimiento: perspectivas latinoamericanas. Revista Internacional de Ciencias Sociales y Humanidades. SOCIOTAM. Vol. XVIII. No. 1. Universidad Autónoma de Tamaulipas. México.

Romero C., R. 2008. Modernidad, América Latina y ciencias sociales. La producción del conocimiento de la sociedad en América Latina. Nómadas. No. 19. Universidad Complutense de Madrid.

Serrano, A. y E. Crespo. 2002. El discurso de la Unión Europea sobre la sociedad del conocimiento. Revista Española de Investigaciones Sociológicas. No. 97. Centro de Investigaciones Sociológicas. Madrid. España.

Sieglin, V. 2007. Sociedad del conocimiento y ciencias sociales. Ciencia UANL. Vol. X. No. 2. Universidad Autónoma de Nuevo León. México.

Sinay, S. 2007. La masculinidad tóxica. Un paradigma que enferma a la sociedad y amenaza a las personas. Ediciones B. Buenos Aires.

Touraine, A. 1973. La sociedad posindustrial. Ariel. Barcelona. 